ISSN 1991-8631

Original Paper

http://indexmedicus.afro.who.int

\title{
Morphometric studies of thyroid gland of Wistar rats exposed to alcohol during pregnancy and/or lactation
}

\author{
Josephat Edoga ONU ${ }^{1 *}$, Bankole Olusiji OKE ${ }^{2}$, Peter Chuka OZEGBE ${ }^{2}$ and \\ Johnson Oluwayemisi OYEWALE ${ }^{3}$
}

${ }^{1}$ Department of Veterinary Anatomy, Usmanu Danfodiyo University, Sokoto, Nigeria. ${ }^{2}$ Department of Veterinary Anatomy, Faculty of Veterinary Medicine, University of Ibadan, Ibadan, Nigeria. ${ }^{3}$ Department of Veterinary Physiology, Biochemistry and Pharmacology, Faculty of Veterinary Medicine, University of Ibadan, Ibadan, Nigeria.

*Corresponding author, E-mail: josephatedoga@yahoo.co.uk

\begin{abstract}
Maternal alcohol consumption during pregnancy and lactation results to some developmental defects such as microcephaly, impairment of central nervous system and mental retardation in the offspring. However, information is limited on the effects of alcohol on the organs of dams being exposed during pregnancy and/or lactation including the thyroid gland. Rat model was employed to investigate the morphometric effects of alcohol on the thyroid gland in dams. 75 female Wistar rats assigned to 3 groups of 25 each were used. Group 1 served as control (C), group 2 and 3 were exposed to alcohol during pregnancy and lactation (APL) and during lactation only (AL) respectively. At Day (D)7, D14, D21, D35 and D49 postpartum, 5 lactating rats were randomly selected from the three groups and sacrificed. After the sacrifice, the thyroids were dissected out and their weights determined. Thereafter, thyroid tissues were fixed in Bouin's fluid and prepared for routine histological examination. The results of the investigation showed significant reduction $(p<0.05)$ in the weights of the thyroid glands. Histological evaluation showed reduced diameter of thyroid follicles, disorganization of follicular cells and desquamation of follicular cells of thyroid glands in alcohol-exposed rats. Our findings suggest that alcohol intake during pregnancy and/or lactation could be injurious to the thyroid glands.
\end{abstract}

(C) 2012 International Formulae Group. All rights reserved.

Keywords: Alcohol, pregnancy, lactation, thyroids, Wistar rats.

\section{INTRODUCTION}

Alcohol-related problems now rank among the world's major health concerns, not only in industrialized countries but also in developing ones (Scraag, 1995). Effects on virtually every major system and organs have been observed in alcoholic patients. Statistics indicate that alcohol consumption is on the increase (Van-Beer, 2004) and is consumed by people for a variety of reasons. Such reasons include entertainment and as a means of reducing stress and emotional upset and these reasons do not go away when women get pregnant (Nucleus Medical Art, 2004). It has been observed that alcohol consumption during pregnancy leads to Foetal Alcohol Syndrome (FAS) in humans and other species which is characterized by growth deficiency, microcephaly and central nervous system dysfunction (Maisto et al., 1999). 
Since the recognition of FAS, numerous animal studies over the years have demonstrated the deleterious effects of alcohol administration during pregnancy and lactation on the offspring (Onu et al., 2010, Onu et al., 2011), with little attention paid to the dams whose anatomy and physiology can be affected by alcohol. There is paucity of data in the literature on the effects of alcohol on the morphometry of thyroid gland in dams exposed to alcohol during pregnancy and/or lactation. The thyroid gland is an essential endocrine gland in mammals and it plays an important role in the regulation of growth and heat production as well as calcium control in the blood (Joel et al., 2009). Research in pregnant animals has shown that alcohol consumption may reduce the levels of thyroid stimulating hormone in the blood but not in the pituitary, suggesting that alcohol alters maternal hypothalamic-pituitary-thyroid activity (Cudd et al., 2002). Abnormal thyroid hormone system function in the mother or foetus(es) during pregnancy can result in brain defects, some of which resemble those found in children with FAS (Cudd et al., 2002). The aim of this study is to evaluate, using rat model, the effects of alcohol on the morphometry of thyroid gland in rats exposed to alcohol during pregnancy and/or lactation.

\section{MATERIALS AND METHODS Experimental animals}

Seventy five female Wistar rats aged between 4 and 5 weeks were used in this investigation. The rats were obtained from the Laboratory Animal Unit, Faculty of Veterinary Medicine, University of Ibadan, Nigeria. All the animals were fed water and commercial diet (Guinea Feed, Bendel Feed and Flour Mills, Nigeria Plc.) ad libitum throughout the duration of the study. After acclimatization for five weeks, the 75 female rats were divided into 3 groups of 25 each. Group 1 served as control (C), group 2 was exposed to alcohol during pregnancy and lactation (APL) while group 3 was exposed to alcohol during lactation only (AL).

\section{Breeding of experimental rats}

At the commencement of the study, the female rats weighing 145-170 $\mathrm{g}$ were bred overnight by introducing 1 male rat into a cage housing 5 female rats. Day 1 of pregnancy was presumed after observing vaginal/copulation plug the following morning.

\section{Alcohol administration \\ Following pregnancy detection by observation of the vaginal/copulation plug (Nwaogu and Ihemelandu, 1999), $2 \mathrm{~g} / \mathrm{kg}$ body weight of $30 \%$ ethanol (v/v) was given to the pregnant rats in APL per os (Maier and West, 2004). This treatment continued throughout pregnancy and lactation. After delivery, the lactating rats in $\mathrm{AL}$ were given the same quantity of ethanol per os and this lasted throughout lactation period.}

\section{Sample collection}

At Day (D) 7, 14, 21, 35 and 49 postpartum, 5 lactating rats each from the 3 groups (Control, APL and AL) were sacrificed and their thyroid glands dissected out.

\section{Quantitative measurements}

The dissected thyroid glands were weighed using Metler's Analytical Balance (MICROWA SWISS 5540). The weights obtained were then expressed as percentage of gross body weight (Relative organ weights) (Riser and Shirer, 1967) for comparison.

\section{Histology}

After determination of the weights, thyroid tissues were fixed in Bouin's fluid for 24 hours. Thereafter, the tissues were dehydrated through a graded series of ethanol (50\%, 70\%, 90\% and 100\%), cleared in xylene, infiltrated with paraffin and embedded in fresh molten paraffin. Hard blocks containing the tissues were then sectioned by 
microtome blade to 5-6 $\mu \mathrm{m}$. The sections were then stained with haematoxylin and eosin (H\&E) and then evaluated for histological changes under the light microscope and photomicrographs were produced.

\section{Statistical analysis}

The data generated from all the measurements were subjected to statistical analyses. Means and standard errors of means (means \pm SEM) were calculated for each group. Statistical differences between the mean values of the relative weights of thyroid gland and diameter of thyroid follicles were analyzed using One-way analysis of variance (ANOVA) and Duncan's Multiple Range Test (DMRT) (Duncan, 1955). For the statistical analysis, $\mathrm{P}<0.05$ was considered statistically significant.

\section{RESULTS AND DISCUSSION}

Table 1 illustrates that the relative weights of thyroid glands were significantly decreased $(\mathrm{P}<0.05)$ in APL at D7, D14 and D21 and in AL at D7 and D14 as against their respective control groups. There was a significant reduction $(\mathrm{P}<0.05)$ in the diameter of thyroid follicles in APL and AL at D7, D14, D21 and D35 when compared with their respective control groups (Table 2). At D35 and 49, the thyroid glands of the rats of the control showed normal thyroid histology with follicular cells lining the basement membrane. However, histological evaluation of the APL and $\mathrm{AL}$ at the same period of study showed disorganization of follicular cells and basement membrane and also desquamation of follicular cells (Figure. 1)

The reason for reduced weight of thyroid glands was not determined in this investigation. However, this could be due to malnutrition caused by alcohol intake since it suppresses appetite thereby reducing food consumption (Techino, 2008). Though the amount of food consumed during alcohol administration was not determined, Di Battista (1989) had earlier reported that golden hamsters exposed to alcohol during pregnancy and lactation consumed less amount of food in relation to the controls. The results obtained therefore, suggest that the reduced weight of the glands could have been caused by a combination of malnutrition and reduced dietery intake.

The reason for the histomorphometrical effects was not known for certain. However, it has been reported that thyroid hormone system functions abnormally in chronic alcoholics (Cudd et al., 2002). It has been observed that alcohol consumption leads to elevation in maternal cortisol levels (Mennella et al., 2005) and previous study (Peteranderl et al., 2002) had earlier demonstrated that cortisol can suppress secretion of basal thyroid stimulating hormone (TSH) and sensitivity of the thyrothrophs. This effect, according to Mc Ewen (1994) is brought about by the action of cortisol on the hypothalamic-pituitary-thyroid axis because hypercortisolism is associated with suppression of TSH. Therefore, the decrease in relative weights and follicular diameter of the thyroid glands in this investigation could be due to lack of stimulation by TSH which has been shown to be reduced in alcoholconsuming pregnant women (Wilcoxon and Redei, 2004). The decrease in the relative weights of thyroid glands as observed in this investigation could be indicative of hypothyroid induced by the alcohol administration. The probability of interference of alcohol in the synthesis and/or secretion of thyroid hormone by the thyroid follicular cells is supported by the histomorphometric observation. This shows that alcohol has destructive effect on the thyroid glands and this may be one of the means by which alcohol consumed during pregnancy and/or lactation affects the growth of the offspring. Thyroid glands play an important role in the regulation of growth (Joel et al., 2009). 
Table 1: Mean ( \pm SEM) relative weights $(\%)$ of thyroid gland of Wistar rats exposed to alcohol during pregnancy and/or lactation.

\begin{tabular}{lcccc}
\hline $\begin{array}{l}\text { Period of } \\
\text { lactation }(\mathbf{D})\end{array}$ & Control $(\mathbf{n}=\mathbf{5})$ & APL $(\mathbf{n}=\mathbf{5})$ & AL $(\mathbf{n}=\mathbf{5})$ & P-value \\
\hline 7 & $0.008 \pm 0.000^{\mathrm{a}}$ & $0.005 \pm 0.000^{\mathrm{c}}$ & $0.006 \pm 0.000^{\mathrm{b}}$ & $* * *$ \\
14 & $0.008 \pm 0.000^{\mathrm{a}}$ & $0.005 \pm 0.000^{\mathrm{c}}$ & $0.006 \pm 0.000^{\mathrm{b}}$ & $* * *$ \\
21 & $0.007 \pm 0.001^{\mathrm{a}}$ & $0.004 \pm 0.000^{\mathrm{c}}$ & $0.006 \pm 0.000^{\mathrm{a}}$ & $* *$ \\
35 & $0.007 \pm 0.000^{\mathrm{a}}$ & $0.004 \pm 0.000^{\mathrm{b}}$ & $0.007 \pm 0.001^{\mathrm{a}}$ & $* * *$ \\
49 & $0.007 \pm 0.001$ & $0.007 \pm 0.000$ & $0.007 \pm 0.002$ & $\mathrm{~ns}$ \\
\hline
\end{tabular}

$* * \mathrm{p}<0.01, * * * \mathrm{p}<0.001 ;$ Values in the same row with different superscripts are significantly different at $\mathrm{p}<0.05$ $\mathrm{n}=$ number of animals; $\mathrm{ns}=$ no significant difference; $\mathrm{APL}=$ Alcohol-exposed rats during pregnancy and lactation $\mathrm{AL}=$ Alcohol-exposed rats during lactation only.

Table 2: Mean ( \pm SEM) diameter of thyroid follicles of Wistar rats exposed to alcohol during pregnancy and/or lactation.

\begin{tabular}{lcccc}
\hline Period of lactation $(\mathbf{D})$ & Control $(\mathbf{n}=\mathbf{5})$ & APL $(\mathbf{n}=\mathbf{5})$ & AL $(\mathbf{n}=\mathbf{5})$ & P-value \\
\hline 7 & $57.00 \pm 1.00^{\mathrm{a}}$ & $38.00 \pm 2.00^{\mathrm{b}}$ & $50.00 \pm 2.00^{\mathrm{c}}$ & $*$ \\
14 & $59.00 \pm 2.00^{\mathrm{a}}$ & $34.00 \pm 2.00^{\mathrm{b}}$ & $44.00 \pm 2.00^{\mathrm{c}}$ & $*$ \\
21 & $62.00 \pm 2.00^{\mathrm{a}}$ & $33.00 \pm 4.00^{\mathrm{b}}$ & $41.00 \pm 2.00^{\mathrm{b}}$ & $* *$ \\
35 & $65.00 \pm 2.00^{\mathrm{a}}$ & $45.00 \pm 1.00^{\mathrm{b}}$ & $52.00 \pm 1.00^{\mathrm{b}}$ & $* *$ \\
49 & $67.00 \pm 2.00$ & $64.00 \pm 2.00$ & $65.00 \pm 2.00$ & $\mathrm{~ns}$
\end{tabular}

${ }^{*} \mathrm{p}<0.05, * * \mathrm{p}<0.01$; Values in the same row with different superscripts are significantly different at $\mathrm{p}<0.05$

$\mathrm{n}=$ number of animals; $\mathrm{ns}=$ no significant difference; $\mathrm{APL}=$ Alcohol-exposed rats during pregnancy and lactation

$\mathrm{AL}=$ Alcohol-exposed rats during lactation only. 

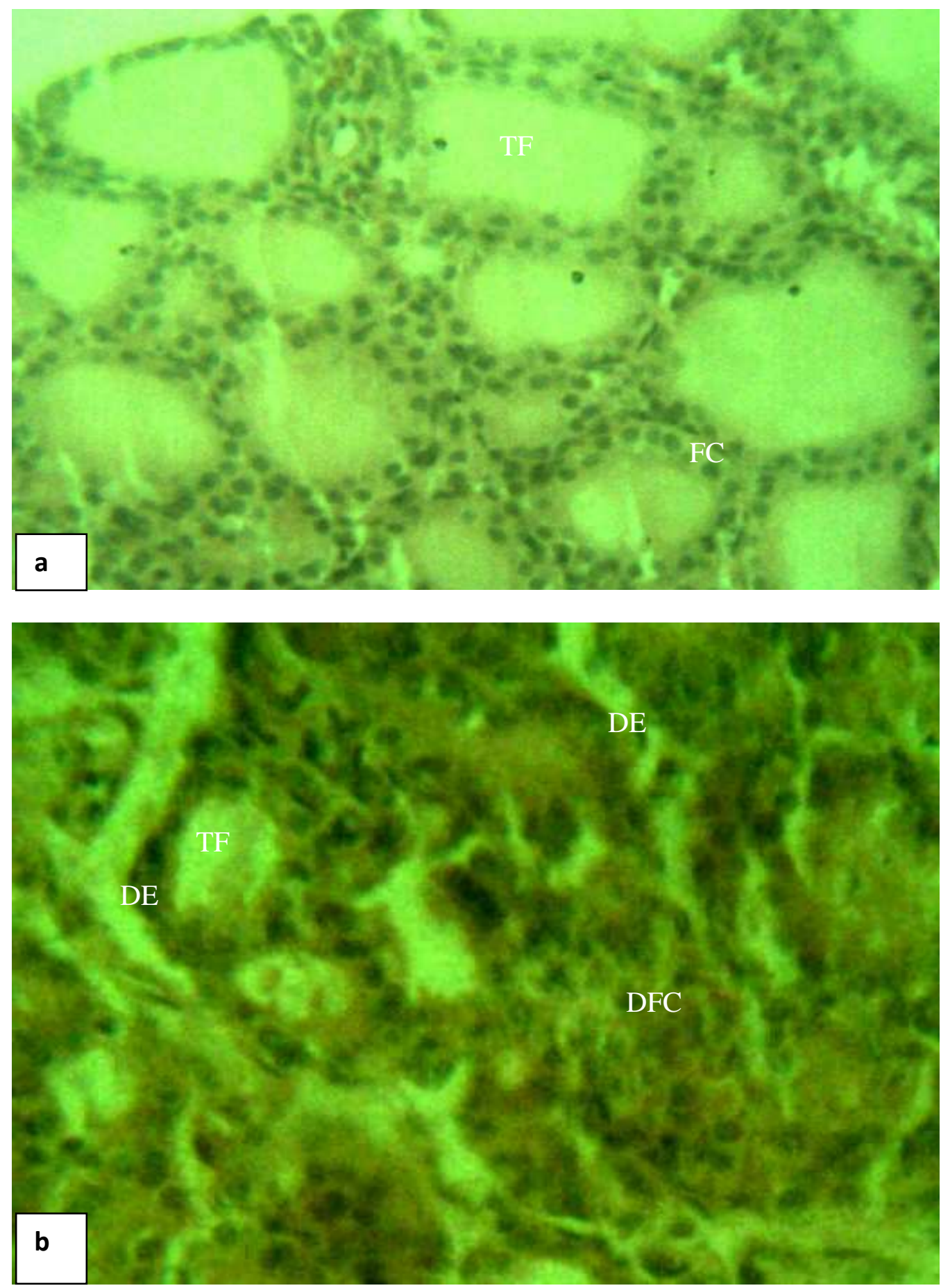

Figure 1: Photomicrograph of thyroid gland of Wistar rats at D 35 and 49. a) Control showing normal thyroid follicles (TF) and follicular cells (FC). b) APL and AL showing thyroid follicles (TF), disorganized follicular cells (DFC) and desquamated epithelium (DE). X400; H\&E Stain.

\section{Conclusion}


The results of this investigation suggest that alcohol consumed during pregnancy and/or lactation could be harmful to the organs of the dams including the thyroid gland.

\section{REFERENCES}

Cudd TA, Chen WA, West, JR. 2002. Foetal and Maternal thyroid hormone responses to ethanol exposure during the third trimester equivalent of pregnancy in Sheep. Alcoholism Clin. Exp. Res., 26(1): 53-58.

Di Battista D. 1989. Voluntary ethanol consumption during pregnancy and lactation in golden hamster. Physiol. Behav., 46: 771-773.

Duncan DB. 1955. Multiple Range and Multiple Fishers Tests. Biometrics, 2: 142.

Joel RU, Ogbole GI, Obajimi, MO, Langundoye, SB. 2009. Ultrasonographically determined thyroid volume in pregnant Nigerian Women. African $J$. Med. Med. Sci., 38: 235-242.

Maier SE, West, JR. 2004. Patterns of alcohol-related birth defects. National Institute on alcohol Abuse and Alcoholism. Bethesda, Maryland hppt://www.niaaa.nih.gov.

Maisto SA, Galizio M, Connors G. 1999. Drug Use and Abuse ( $3^{\text {rd }}$ edn). Harcourt Bruce College Publishers: Montreal, Canada.

Mc Ewen BS. 1994. Corticosteroids and hippocampal plasticity. Annals NY Acad. Sci., 746: 134-142.

Mennella JA, Pepino MY, Teff KL. 2005. Acute alcohol consumption disrupts the hormonal milieu of lactating women. The J. Clin. Endocrinol. Met., 90: 1979-1985.

Nucleus Medical Art. 2004. Smoking, alcohol and pregnancy Retrieved March 20, 2005 from http:// www.yourmedicalsource.com

Nwaogu IC, Ihemelandu EC. 1999. Effects of maternal alcohol consumption on the allometric growth of muscles in foetal and neonatal rats. Cells Tis Org., 164: 167-173.

Onu JE, Ezeasor DN, Ihemelandu EC. 2010. Effects of maternal alcohol consumption on epididymal growth in neonatal mice. Nig. Vet. J., 31: 279-282.

Onu JE, Oke BO, Ozegbe PC. Oyewale, JO. 2011. Morphophysiological evidence for delay in puberty in female Wistar rats whose dams were exposed to alcohol during pregnancy and/or lactation. Int. J. Biol. Chem. Sci., 5(2): 546-553.

Peteranderl C, Antonijevic IA, Steiger A, Muruck H, Held K, Frieboes RM, Uhr M, Schaaf L. 2002. Nocturnal secretion of TSH and ACTH in male patients with depression and healthy controls. J Psych Res., 36: 189-196.

Riser WH, Shirer JF. 1967. Correlation between canine hip dysplasia and pelvic muscle mass. A study of 95 dogs. $J$. Amer. Vet. Res., 28: 767-777.

Scraag R. 1995. A quantification of alcoholrelated mortality in New Zealand. Australian New Zealand J. Med., 25: 511.

Techino G. 2008. Alcoholic diseases in hepato-gastroenterology: a point of view. Hepatogastroenterolgy., 55(82-83): 371378.

Van-Beer K. 2004. Alcohol, the Fetus and Fetal Alcohol Syndrome. Retrieved November 1, 2008 from htt://www.arium.org

Wilcoxon JS, Redei EE. 2004. Prenatal programming of adult thyroid function by alcohol and by alcohol and thyroid hormone. Amer $J$ Physiol Endocrinol Met., 287(2): 318-326. 